\title{
Nonlinear Organic Dielectrics for Energy Storage Applications
}

\author{
Lev Mourokh ${ }^{1,2,3}$, Yan Li ${ }^{3}$, Robert Gianan33, Pavel Lazarev³ \\ ${ }^{1}$ Department of Physics, Queens College of the City University of New York, Flushing, USA \\ ${ }^{2}$ The Graduate Center of CUNY, New York, USA \\ ${ }^{3}$ Capacitor Sciences Inc., Menlo Park, USA \\ Email: lev.murokh@qc.cuny.edu
}

How to cite this paper: Mourokh, L., Li, Y., Gianan, R. and Lazarev, P. (2019) Nonlinear Organic Dielectrics for Energy Storage Applications. Materials Sciences and Applications, 10, 33-44.

https://doi.org/10.4236/msa.2019.101004

Received: November 27, 2018

Accepted: January 8, 2019

Published: January 11, 2019

Copyright (c) 2019 by author(s) and Scientific Research Publishing Inc. This work is licensed under the Creative Commons Attribution International License (CC BY 4.0).

http://creativecommons.org/licenses/by/4.0/

\begin{abstract}
We present the feasibility study of nonlinear dielectrics for the energy storage applications. Corona deposition of electric charges to the surface of thin films of highly polarizable organic molecules (dielectrophores) shows that the electric field inside the dielectric has a highly nonlinear response. The stored energy densities are superior to the polypropylene films, measured for the comparison, and at least comparable to the current electrochemical batteries. These results make us believe that the dielectrophores-based electrostatic capacitors can revolutionize the energy storage market.
\end{abstract}

\section{Keywords}

Nonlinear Dielectrics, Energy Density, Corona Charge Poling, Organic Thin Films

\section{Introduction}

Efficient energy storage is important both for everyday operations and for the long-term sustainability of human civilization. Electrochemical storage units, such as batteries, have large energy density but small power density and, moreover, can degrade relatively fast. Electrostatic storage units, such as capacitors, have the advantages over the batteries in almost all areas but have much smaller energy density [1]. Correspondingly, researchers are extensively looking for the opportunity to increase it. Recently, we outlined the requirements and design rules for dielectric materials which should be implemented in prospective electrostatic capacitors [2]. The molecular unit (dielectrophore) must contain three main components: a polarizable subunit having large field induced electric dipole, an isolating subunit which prevents current leakage, and a structural ele- 
ment that promotes self-assembly of molecules in solution and in mesophase and promotes crystallization in the process of film formation. We also showed [3] that if the induced dipole of the dielectrophore depends nonlinearly on the external electric field, at high operating voltage such structure can have the energy density comparable with that of the batteries and even exceed it.

Linear capacitors are characterized by capacitance, the ratio between the stored charge and the applied voltage. The capacitance is determined by the geometry and the permittivity of the dielectric material. If the dielectric is highly nonlinear, the concept of permittivity is no longer applicable and we have to introduce a new quantity to compare the performance of various dielectrics. It is natural that such quantity would be the stored energy, in a general case defined as

$$
W=\int_{0}^{Q_{f}} V(Q) \mathrm{d} Q
$$

where $Q$ is the total free charge in the system. Free charges are deposited until $Q_{f}$ is reached and the dielectric molecules are polarized with a creation of bound charges. The dielectric molecules are kept at equilibrium by means of stretching and twisting of the bonds [4], so only free charges are included in Equation (1). For the linear case, when $V=Q / C$, Equation (1) reduces to a well-known expression

$$
W=Q_{f}^{2} / 2 C
$$

To compare the obtained stored energy to currently available commercial devices, it is convenient to express it as specific energy measured in Watt hours per kilogram, as

$$
\frac{W}{M}(\mathrm{Wh} / \mathrm{kg})=\int_{0}^{Q_{f}} V(Q) \mathrm{d} Q / 3600 A d \rho,
$$

where $A$ is the area of the electrodes, $d$ is their separation, and $\rho$ is the mass density of the dielectric material.

Evaluation of the potential materials at high electric field $(0.1-1.0 \mathrm{~V} / \mathrm{nm})$ represents a significant challenge. There are several approaches to achieve that. The most straightforward method is to grow a thin film between two metallic electrodes, similar to the usual parallel plate capacitor geometry. Such nonlinear effect as a second harmonic generation was studied previously using this approach [5]. However, in this case there are many factors limiting the value of the applied field. In particular, small shunts in the thin film can lead to the current leakage and reduction of the amount of the charge accumulated on the electrodes. Also, the roughness of the electrode surface might produce the nonuniform growth of the polar material which decreases the breakdown voltage [6].

In the present studies, we use another approach, the corona deposition of ions on the top surface of film [7]. In this method, electrons in the surrounding gas 
are accelerated to high energies and ionize the gas molecules after the collisions. By applying different voltage polarities between the sample and the plasma source, one can achieve the deposition of negative or positive ions of the atmosphere gas ( $\mathrm{He}, \mathrm{N}_{2}$, or air) on the surface of the film. The deposited charges serve as the top electrode, while the bottom electrode is grounded to allow its charging with opposite sign from the ground. This method achieves high and controllable values of applied electric field and has been extensively used for the studies of the second harmonic generation in polymers (for review, see Ref. [8]). Moreover, this approach (bringing the charges in a bit in time) is very similar to the gedanken experiment led to the derivation of Equation (1), so it is appropriate for material characterization for energy storage.

\section{Methods}

\subsection{Experimental Procedure}

The setup of the corona charge deposition method is shown in Figure 1. Our measurement device consists of the corona bar which induces the electric breakdown of surrounding gas and directs the positive or negative ions toward the thin film surface; the amperemeter measures the current from (to) the ground to (from) the bottom electrode associated with its charging opposite to the deposited ions; and the Kelvin probe apparatus measures the surface potential with the respect to the ground [9].

The tested area, $A$, is initially placed under the corona bar and charged for period of time $\Delta t_{1}$. The bottom electrode current, $J_{\mathcal{O}}$ is simultaneously measured. Then, the tested area is placed under the Kelvin probe to measure the surface potential $V_{S}$. Thereafter, the sample is placed back under the corona bar and charged again for the period of time $\Delta t_{2}$, the surface potential is measured again and the procedure is repeated $N$ times. Correspondingly, the density of the deposited charge in the nth step is $\sigma_{n}=J_{c} \Delta t_{n} / A$, where $n=1,2, \cdots, N$, and the total charge density at the top surface of this film is given by

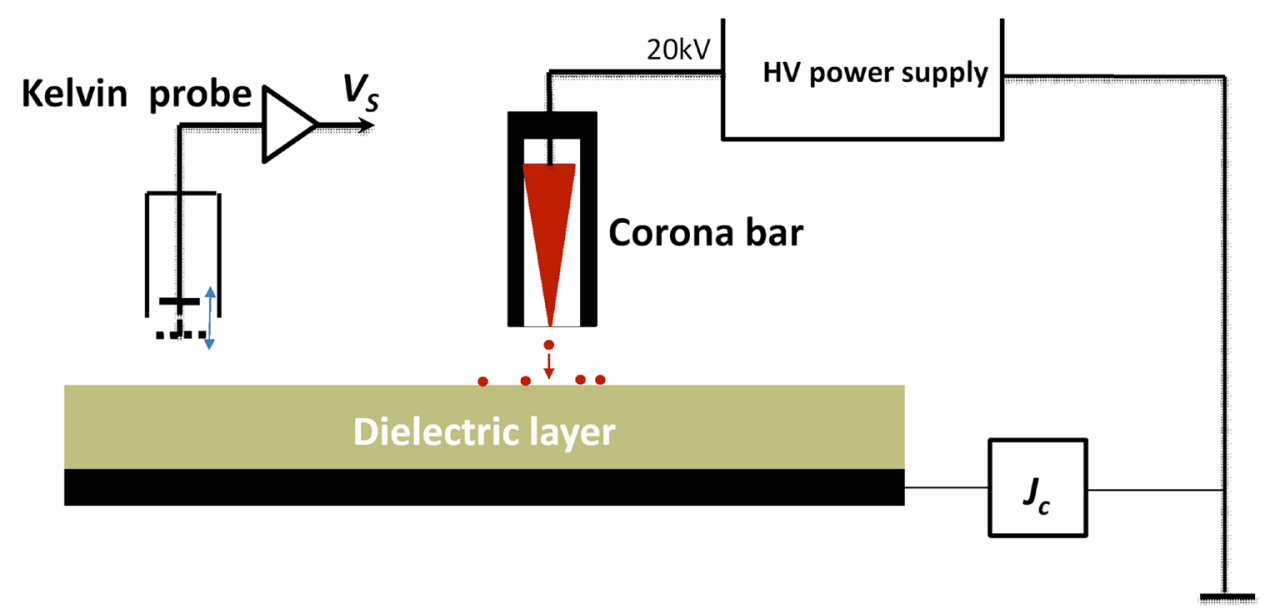

Figure 1. Schematic diagram of the experimental setup for the corona charge deposition and Kelvin probe measurements. 


$$
\sigma=J_{c} t / A
$$

where $t$ is the total time under the corona charge deposition.

To calibrate our apparatus and to compare our samples with a well-known material, we perform the corona deposition of positive charges and Kelvin probe measurements for a thin polypropylene film. The current from the bottom electrode to the ground is kept at $J_{c}=10^{-5} \mathrm{~A}$. The results are shown in Figure 2 for two different films. Figure 2(a) shows the surface voltage measured as time elapsed with both films initially negatively charged. In both cases, after approximately 10 seconds of the charge deposition, the electric breakdown occurs, and the polypropylene films are damaged.

To verify the results of our measurements, we recalculate the surface voltage to the electric field across the $6 \mu \mathrm{m}$ thick film and adjust our data to the initial condition of the zero charge. Using Equation (4), we express the time of Figure 2 (a) in terms of the density of the deposited charges for our sample of the size $11.5 \times 6 \mathrm{~cm}^{2}$. The resulting relation between the charge density and the electric field is shown in Figure 2(b). The straight line representing the linear fit of the low-field data for both films can be used for the determination of the dielectric constant. According to Gauss' Law [4], the electric displacement is equal to the surface charge density, and the dielectric constant is given by

$$
\varepsilon=\sigma / \varepsilon_{0} E \approx 2.9 \text {. }
$$

The obtained result is in a good agreement with the tabulated value for the polypropylene films [10], so we have verified the reliability of our approach.

\subsection{Molecular Synthesis and Film Growth}

In the present paper, we examine thin films based on three dielectrophores shown in Figure 3, as we believe that they are promising for high specific energy capacitors. They are all synthesized from the Disperse Red 1 or similar Fast
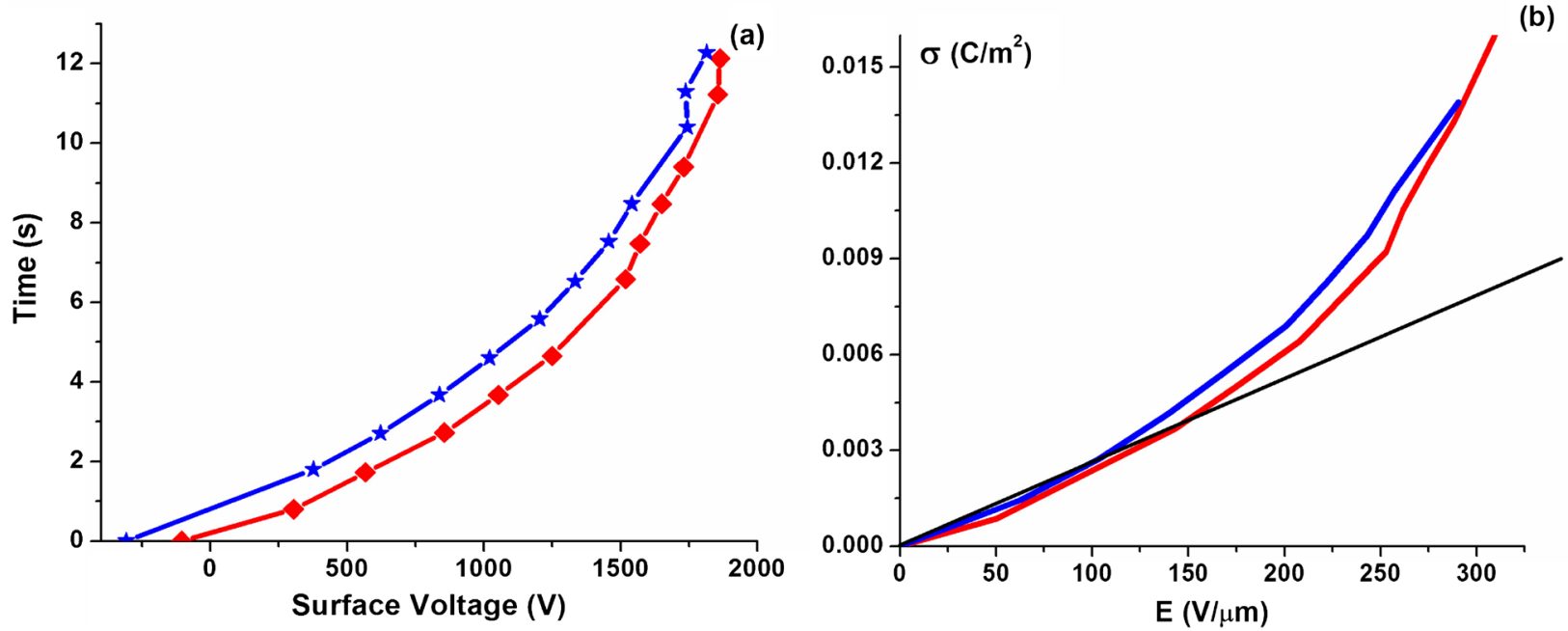

Figure 2. (a) Measured surface voltage under the corona charge deposition; (b) Dependence of the electric field applied to the polypropylene film on the density of the deposited charges. 


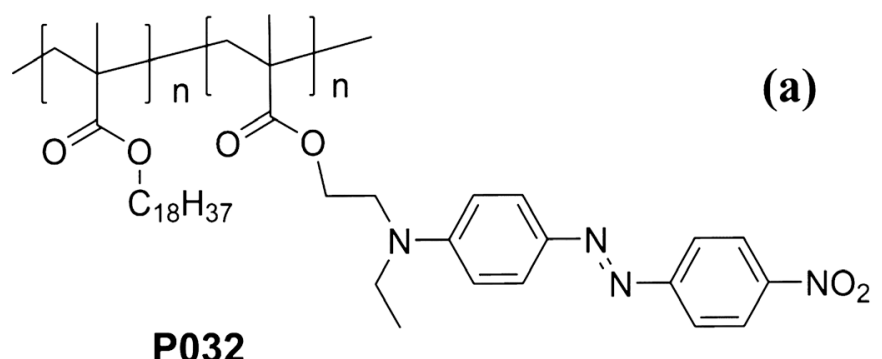

P032

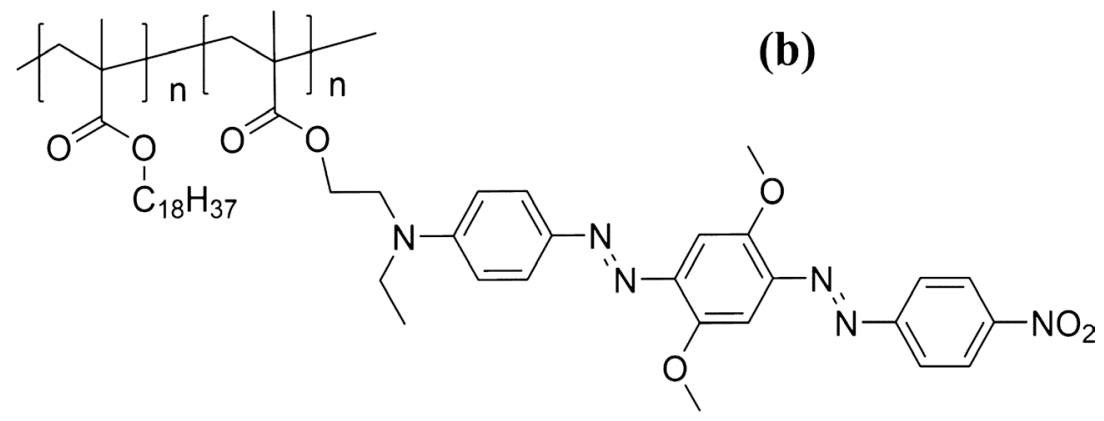

P033

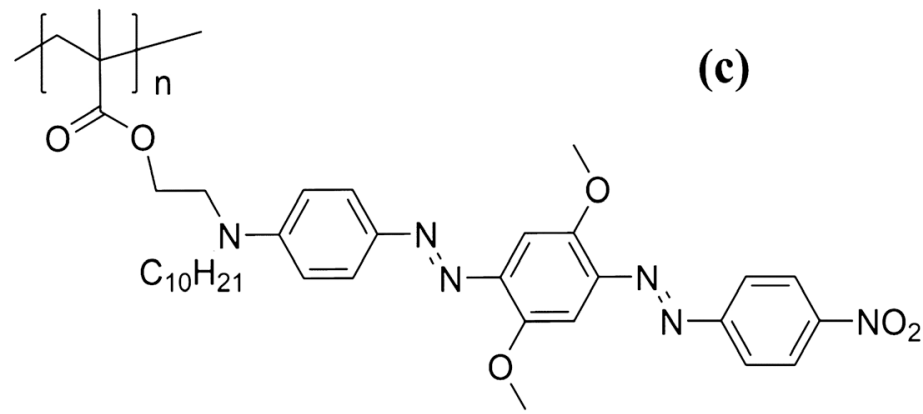

P036

Figure 3. Dielectrophores used for the thin films. (a) P032, (b) P033, and (c) P036.

Black K salt molecules demonstrating pronounced nonlinear properties in optical experiments [11].

P032 molecule contains two benzene rings with azo connection, while P033 and P036 molecules contain three benzene rings each. In all cases, the amino groups are used as the electron donors. All reagents were purchased from bestknown commercial sources, such as Sigma Aldrich, Thermo-Fisher, and VWR, and used without further purification.

P032 Synthesis (Scheme 1) is shown in Figure 4.

(E)-2-(ethyl(4-((4-nitrophenyl)diazenyl)phenyl)amino)ethyl methacrylate (J074). To the solution of Disperse Red-1 $(6.0 \mathrm{~g}, 19.1 \mathrm{mmol})$ and triethylamine $(3.2 \mathrm{~mL}$, $23 \mathrm{mmol})$ in THF $(80 \mathrm{~mL})$, was dropwise added methacryloyl chloride $(2.2 \mathrm{~mL}$, $1.2 \mathrm{mmol}$ ) at $0^{\circ} \mathrm{C}$. The resulting solution was allowed to warm to room temperature and stirred overnight. The reaction solution was filtered and the filtrate was concentrated under reduced pressure. The residue was taken into $200 \mathrm{~mL}$ 


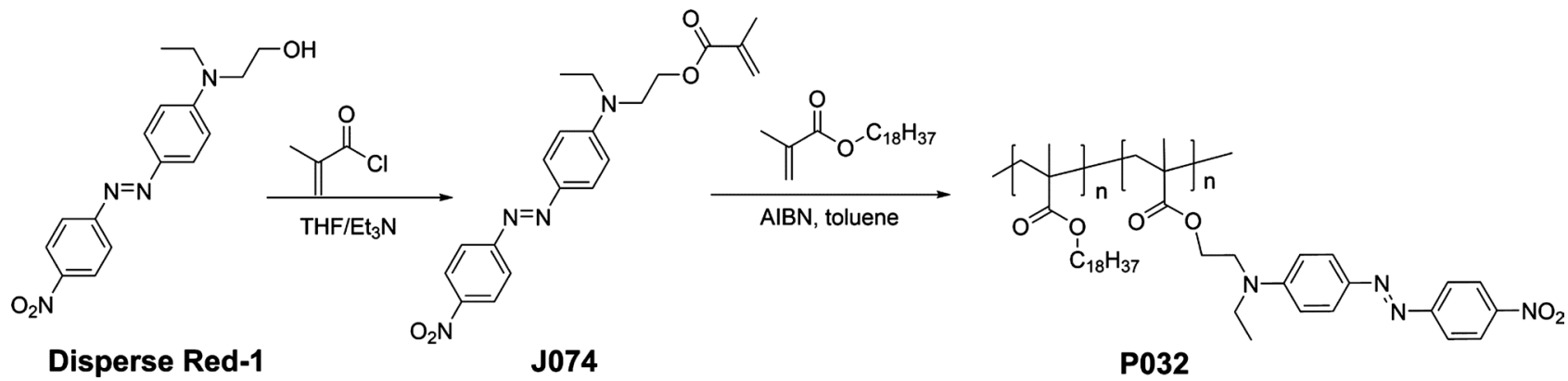

Figure 4. Scheme 1: Synthetic scheme of P032.

ethyl acetate, and the solution was washed with water $(100 \mathrm{~mL} \times 3)$ and brine $(100 \mathrm{~mL})$. The organic layer was separated, dried over $\mathrm{MgSO}_{4}$, and concentrated under reduced pressure. The crude product was purified through column chromatography ( $10 \%$ to $20 \%$ ethyl acetate in hexane gradient flush) to yield $4.5 \mathrm{~g}$ of pure J074. ${ }^{1} \mathrm{H}$ NMR (400 MHz, Chloroform-d) $\delta 8.33(2 \mathrm{H}, \mathrm{d}, \mathrm{J}=8.9 \mathrm{~Hz}$ ), 7.92 $(4 \mathrm{H}, \mathrm{t}, \mathrm{J}=8.7 \mathrm{~Hz}), 6.83(2 \mathrm{H}, \mathrm{d}, \mathrm{J}=9.2 \mathrm{~Hz}), 6.11(1 \mathrm{H}, \mathrm{s}), 5.60(1 \mathrm{H}, \mathrm{t}, \mathrm{J}=1.6 \mathrm{~Hz})$, $4.38(2 \mathrm{H}, \mathrm{t}, \mathrm{J}=6.2 \mathrm{~Hz}), 3.74(2 \mathrm{H}, \mathrm{t}, \mathrm{J}=6.3 \mathrm{~Hz}), 1.95(3 \mathrm{H}, \mathrm{s}), 1.27(3 \mathrm{H}, \mathrm{t}, \mathrm{J}=7.1$ $\mathrm{Hz})$.

P032: J074 (2.5 g), stearyl methacrylate (2.0 g) and AIBN (40 mg) were dissolved in toluene $(18 \mathrm{~mL})$ and the solution was sparged with Argon for $5 \mathrm{~min}$. The solution was heated to $80{ }^{\circ} \mathrm{C}$ overnight with stirring. The reaction solution was cooled to room temperature and dropwise added in to $300 \mathrm{~mL}$ IPA. The precipitate was collected by suction filtration, washed with fresh IPA (100 mL) 3 times, and dried under vacuum to yield polymer P032 $(3.2 \mathrm{~g})$ as a red solid. ${ }^{1} \mathrm{H}$ NMR (400 MHz, Chloroform-d) $\delta 8.34-8.11$ (2H, br), 7.95 - 7.67 (4H, br), 6.90 6.59 (2H, br), 4.28 - 3.96 (2H, br), 3.95 - 3.77 (2H, br), 3.75 - 3.24 (4H, br), 2.01 1.68 (3H, br), 1.63 - 1.42 (3H, br), 1.38 - 1.08 (34H, br), $1.06-0.64$ (9H, br).

P033 Synthesis (Scheme 2) is shown in Figure 5.

2-((4-((E)-(2,5-dimethoxy-4-((E)-(4-nitrophenyl) diazenyl)phenyl) diazenyl) phenyl)(ethyl) amino)ethan-1-ol (J033). Fast Black K Salt (44.2\%, 126 g) was dissolved in $600 \mathrm{~mL}$ acetonitrile and $600 \mathrm{~mL} \mathrm{NaOAc}$ buffer solution $(\mathrm{pH}=4)$ and the resulting solution was stirred for 1 hour, followed by vacuum filtration. The filtrate was added dropwise to a solution of 2-(ethyl(phenyl)amino)ethan-1-ol (20 $\mathrm{g}$ in $100 \mathrm{~mL}$ acetonitrile) at $0^{\circ} \mathrm{C}-5^{\circ} \mathrm{C}$. The resultant solution was stirred at room temperature for 16 hours and the precipitate was filtered out and washed with a solvent of acetonitrile/water (1:1) and dried under vacuum. The product (31.0 g) was obtained as a black powder.

2-((4-((E)-(2,5-dimethoxy-4-((E)-(4-nitrophenyl)diazenyl)phenyl)diazenyl)ph enyl)(ethyl) amino)ethyl methacrylate (J034). To the solution of compound J033 $(5.0 \mathrm{~g})$ and triethylamine $(4.4 \mathrm{~mL})$ in $50 \mathrm{~mL}$ THF (anhydrous) at $0{ }^{\circ} \mathrm{C}$, was added dropwise to a solution of methacryloyl chloride $(3.1 \mathrm{~mL})$ in THF (anhydrous, 10 $\mathrm{mL}$ ). The resulting solution was warmed up to room temperature and was stirred overnight at room temperature. The reaction solution was filtered and THF was used to wash the insoluble; the filtrate was concentrated under vacuum 

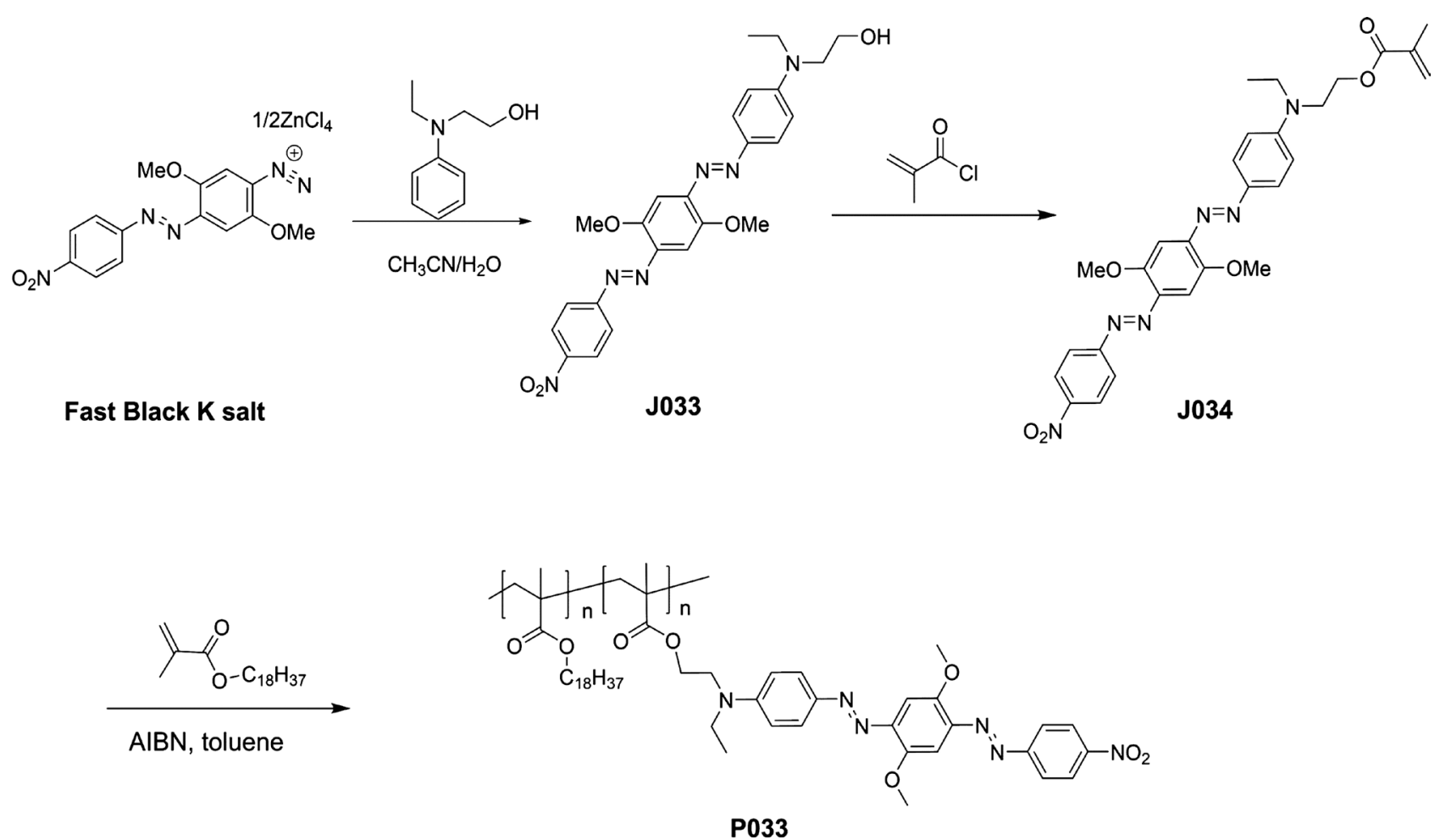

Figure 5. Scheme 2: Synthetic scheme of P033.

and diluted in dichloromethane. The diluted solution was washed with water and the solvent was removed under vacuum. The crude product was purified with column chromatography (20\% ethyl acetate in hexane) and $3.2 \mathrm{~g}$ pure product was isolated as a black powder. ${ }^{1} \mathrm{H}$ NMR (400 MHz, Chloroform-d) $\delta$ 8.41 - $8.32(\mathrm{~m}, 2 \mathrm{H}), 8.07$ - $7.99(\mathrm{~m}, 2 \mathrm{H}), 7.96-7.89(\mathrm{~m}, 2 \mathrm{H}), 7.47(\mathrm{~d}, \mathrm{~J}=16.0 \mathrm{~Hz}$, $2 \mathrm{H}), 6.81(\mathrm{~d}, \mathrm{~J}=9.2 \mathrm{~Hz}, 2 \mathrm{H}), 6.13-6.08(\mathrm{~m}, 1 \mathrm{H}), 5.62-5.56(\mathrm{~m}, 1 \mathrm{H}), 4.37(\mathrm{t}, \mathrm{J}=$ $6.2 \mathrm{~Hz}, 2 \mathrm{H}), 4.09(\mathrm{~s}, 3 \mathrm{H}), 4.04(\mathrm{~s}, 3 \mathrm{H}) 3.73(\mathrm{t}, \mathrm{J}=6.2 \mathrm{~Hz}, 2 \mathrm{H}), 3.54(\mathrm{q}, \mathrm{J}=7.1 \mathrm{~Hz}$, $2 \mathrm{H}), 1.94(\mathrm{t}, \mathrm{J}=1.3 \mathrm{~Hz}, 3 \mathrm{H}), 1.30-1.21(\mathrm{~m}, 4 \mathrm{H})$.

P033: Compound $2(2.0 \mathrm{~g})$, stearylmethacrylate $(1.2 \mathrm{~g})$ and AIBN (16 mg) were dissolved in anhydrous toluene $(12 \mathrm{~mL})$ in a sealed flask and the resulting solution was heated to $80^{\circ} \mathrm{C}$ for 18 hours and then cooled to room temperature. The polymer was obtained by precipitating in isopropanol. ${ }^{1} \mathrm{H}$ NMR $(400 \mathrm{MHz}$, Chloroform-d) $\delta 8.43-8.22(2 \mathrm{H}, \mathrm{br}), 8.09-7.71(4 \mathrm{H}, \mathrm{br}), 7.50-7.26(2 \mathrm{H}, \mathrm{br})$, $6.88-6.59(2 \mathrm{H}, \mathrm{br}), 4.28-3.75(10 \mathrm{H}, \mathrm{br}), 3.70-3.31(4 \mathrm{H}, \mathrm{br}), 2.11-1.68(3 \mathrm{H}$, br), 1.68 - 1.46 (3H, br), $1.46-0.96$ ( $40 \mathrm{H}, \mathrm{br}), 0.93-0.74(6 \mathrm{H}, \mathrm{br})$.

P036 Synthesis (Scheme 3) is shown in Figure 6.

2-(Decyl(phenyl)amino)ethan-1-ol (J051)

To a 12L three necked round bottom flask equipped with an overhead stirrer and Teflon coated temperature probe was added N-(2-hydroxyethyl)aniline (1785 g, $13.012 \mathrm{~mol}$ ), 1-bromodecane (3333 g, $13.71 \mathrm{~mol}, 1.05$ eq.) and diisopropylethylamine $(2720 \mathrm{~mL}, 15.614 \mathrm{~mol}, 1.2 \mathrm{eq})$. The reaction mixture was stirred at $110 \mathrm{rpm}$ and heated to $90^{\circ} \mathrm{C}$ for 17.5 hours. A $200 \mu \mathrm{L}$ aliquot removed for LCMS (diluted to $1 \mathrm{~mL}$ in DMSO) showed no remaining $\mathrm{N}$-(2-hydroxyethyl)aniline and the 


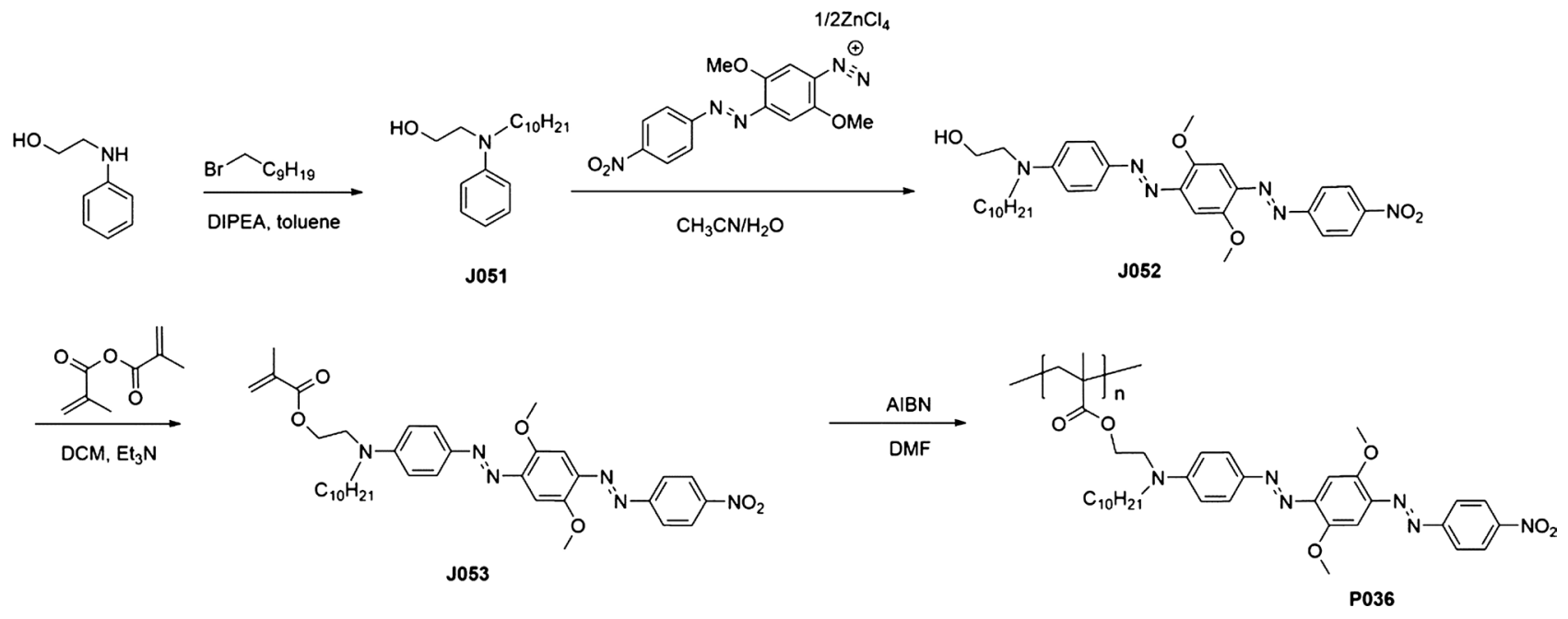

Figure 6. Scheme 3: Synthetic scheme of P036.

appearance of J051. Stirring was stopped and the reaction mixture was cooled to room temperature. The reaction mixture was diluted with ethyl acetate $(3.5 \mathrm{~L})$ and filtered through a medium glass fritted funnel. The ammonium salts were washed with ethyl acetate $(8.5 \mathrm{~L})$ and the salts were discarded as solid waste. The organic phase was washed with deionized water $(3 \times, 4 \mathrm{~L})$ and brine $(1 \times, 1 \mathrm{~L})$. The organics were concentrated under reduced pressure to give crude product (3.56 $\mathrm{kg}, 99 \%)$ as a brown oil.

1H NMR (250 MHz, CDCl3) (ppm): $7.24(\mathrm{t}, 2 \mathrm{H}), 6.68-6.83(\mathrm{~m}, 3 \mathrm{H}), 3.78(\mathrm{t}$, $2 \mathrm{H}), 3.51-3.40(\mathrm{~m}, 2 \mathrm{H}) 3.32(\mathrm{t}, 2 \mathrm{H}), 1.86(\mathrm{br}, 1 \mathrm{H}), 1.32$ - $1.10(\mathrm{br}, 16 \mathrm{H}), 0.90$ $(\mathrm{t}, 3 \mathrm{H})$.

2-(Decyl(4-((E)-(2,5-dimethoxy-4-((E)-(4-nitrophenyl)diazenyl)phenyl)diaze nyl) phenyl) amino)ethan-1-ol (J052).

Fast Black K Salt $(44.2 \%, 10.8 \mathrm{~g})$ was dissolved in $90 \mathrm{~mL}$ acetonitrile and 90 $\mathrm{mL} \mathrm{NaOAc}$ buffer solution $(\mathrm{pH}=4)$ and the resulting solution was stirred for 1 hour, followed by filtration. The filtrate was added dropwise to a solution of compound $\mathrm{J} 051$ ( $2.5 \mathrm{~g}$ in $20 \mathrm{~mL}$ acetonitrile) at $0^{\circ} \mathrm{C}$. The resultant solution was stirred at room temperature for 16 hours and the precipitate was filtered out and washed with mix solvent of acetonitrile/water (1:1) and dried under vacuum. The pure J052 was obtained as a black powder (3.7 g, 70\%).

2-(decyl(4-((E)-(2,5-dimethoxy-4-((E)-(4-nitrophenyl)diazenyl)phenyl)diazen yl) phenyl) amino)ethyl methacrylate (J053).

To a $5 \mathrm{~L}$ round bottom equipped with an internal thermometer and stir bar were added 0052 (303.8 g, $514 \mathrm{mmol}, 1.0 \mathrm{eq})$, dichloromethane (1.5 L) and triethylamine (180 mL, $1286 \mathrm{mmol}, 2.5 \mathrm{eq})$. Methacrylic anhydride (115 mL, 771 mmol, 1.5 eq) was added over 3 minutes at room temperature. After 18 hours, additional methacrylic anhydride $(15 \mathrm{~mL}, 100 \mathrm{mmol}, 0.2 \mathrm{eq})$ was added and the reaction stirred for a further 22 hours. The reaction was filtered through a medium sintered glass funnel to remove salts and the filtrate was concentrated under reduced pressure. Methanol (1L) was added to the residue and the reaction 
rotated on a rotary evaporator at $40^{\circ} \mathrm{C}$ bath for 5 hours. The solid was collected on a sintered glass funnel. The crude solid was transferred to a 3-necked 1L round bottom flask equipped with a mechanical stirrer, methanol $(500 \mathrm{~mL})$ was added and the mixture was stirred 3 hours. The solid was filtered through a sintered glass funnel and rinsed with methanol followed by a hexanes rinse. The reaction was dried under vacuum at $40^{\circ} \mathrm{C}$ to afford $\mathrm{J053}(231.65 \mathrm{~g}, 68 \%)$ as a black solid.

${ }^{1} \mathrm{H}$ NMR (250 MHz, CDCl3) (ppm): 8.4 (d, $\left.2 \mathrm{H}\right), 8.05$ (d, 2H), 7.95 (d, 2H), $7.5(\mathrm{~d}, 2 \mathrm{H}) 6.8(\operatorname{app} \mathrm{d}, 2 \mathrm{H}), 6.1(\mathrm{~s}, 1 \mathrm{H}), 5.6(\mathrm{~s}, 1 \mathrm{H}) 4.4(\mathrm{t}, 2 \mathrm{H}), 4.1(\mathrm{~s}, 3 \mathrm{H}), 4.0(2$, $3 \mathrm{H}), 3.75(\mathrm{t}, 2 \mathrm{H}), 3.4(\mathrm{t}, 2 \mathrm{H}), 1.95(\mathrm{~s}, 3 \mathrm{H}), 1.65(\mathrm{br} \mathrm{s}, 2 \mathrm{H}), 1.25(\mathrm{~m}, 16 \mathrm{H}), 0.85(\mathrm{t}$, $3 \mathrm{H}) .1 \mathrm{H} \mathrm{NMR}(400 \mathrm{MHz}$, Chloroform-d) $\delta 8.43-8.32(2 \mathrm{H}, \mathrm{m}), 8.11-8.01(2 \mathrm{H}$, $\mathrm{m}), 7.98-7.87(2 \mathrm{H}, \mathrm{m}), 7.48(2 \mathrm{H}, \mathrm{d}, \mathrm{J}=16.7 \mathrm{~Hz}), 6.80(2 \mathrm{H}, \mathrm{d}, \mathrm{J}=9.2 \mathrm{~Hz}), 6.11$ $(1 \mathrm{H}, \mathrm{s}), 5.60(1 \mathrm{H}, \mathrm{t}, \mathrm{J}=1.6 \mathrm{~Hz}), 4.37(2 \mathrm{H}, \mathrm{t}, \mathrm{J}=6.2 \mathrm{~Hz}), 4.10(3 \mathrm{H}, \mathrm{s}), 4.05(3 \mathrm{H}, \mathrm{s})$, $3.75(2 \mathrm{H}, \mathrm{t}, \mathrm{J}=6.2 \mathrm{~Hz}), 3.50-3.37(2 \mathrm{H}, \mathrm{m}), 1.74-1.61(2 \mathrm{H}, \mathrm{m}), 1.39-1.22(14 \mathrm{H}$, $\mathrm{m}), 0.97-0.79(3 \mathrm{H}, \mathrm{m})$.

Poly 2-(decyl(4-((E)-(2,5-dimethoxy-4-((E)-(4-nitrophenyl)diazenyl)phenyl) diazenyl) phenyl) amino)ethyl methacrylate (P036)

Compound J053 (5.0 g) and AIBN (50 mg) were dissolved in DMF (50 mL) in a sealed flask; the resulting solution was degassed and heated to $80^{\circ} \mathrm{C}$ for 18 hours and then cooled to room temperature. The reaction solution was concentrated and precipitated in IPA and crude product was washed with IPA to yield P036 (2.5 g). ${ }^{1} \mathrm{H}$ NMR (400 MHz) $\delta 8.26(2 \mathrm{H}$, br) $7.86(4 \mathrm{H}$, br), $7.26(2 \mathrm{H}, \mathrm{br})$, 6.68 (2H, br), 4.01 (8H, br), 3.56 (2H, br), 3.25 (2H, br), 1.95 (2H, br), $1.59(3 \mathrm{H}$, br), 1.17 (14H, br), $0.79(3 \mathrm{H}, \mathrm{br})$.

Synthesized powders of P032, P033, or P036 are dissolved in organic solvent at a concentration of $10 \mathrm{wt} \%$ in preparation for solvent solution coating. Films are prepared using wire-wound wet film applicator rods on a Gardco II Automatic Drawdown Machine. The films are several micrometers thick and grown on either indium-tin-oxide (ITO) or aluminum-coated glass.

\section{Results and Discussions}

The results of the corona experiments for the thin films based on the P032, P033, and P036 dielectrophores are shown in Figure 7 in the form most suitable for the implementation of Equation (3), i.e. as a dependence of the surface potential on the total deposited charge. One can see that for all the films, the initial linear region becomes strongly nonlinear and finally the voltage saturation occurs.

The physics of this saturation can be seen from the definition of the electron displacement (which is equal to the deposited charge density)

$$
D=\varepsilon_{0} E+P,
$$

where $P$ is the polarization of the material. Nonlinear effects become so strong that the increment of the deposited charge leads only to the increase of the polarization with the field (and, consequently, the surface potential) remaining almost unchanged. It is evident from Figure 7 and Equation (6), that the polariza- 
tion for P036 is larger than for P033, which is, in turn, is larger than for P032. It can also be seen from the slope of the linear region which defines the low-field linear permittivity. Both the high-field polarizations and the low-field permitivities for our dielectrophores are significantly larger than that of the polypropylene (PP) film, but the main difference is the material breakdown time, $t_{b d}$. While for PP it is about several seconds, for P032, P033, and P036 tbd is about 2, 5, and 6 hours, respectively. As the charge deposition changes the electric field across the sample insignificantly, it postpones the breakdown and allows us to deposit much more charges and, consequently, increase the amount of the stored energy dramatically.

To make qualitative estimations, we use Equation (3) to calculate the stored energy density for our thin films with areas of $11.5 \times 6 \mathrm{~cm}^{2}$ when they are charged up to the breakdown. The mass density for all the materials is about $1000 \mathrm{~kg} / \mathrm{m}^{3}$. The thicknesses, maximal surface potentials, the films breakdown times, and the obtained energy densities are presented in Table 1 . One can see that the stored energy densities for our dielectrophores are several orders of the magnitude larger than that of the PP film. Moreover, as the current generation of the batteries has the energy densities of hundreds of Watt hours per kilogram [1], the dielectrophores-based capacitors would be at least comparable to the batteries in this parameter, while being superior in all other properties.

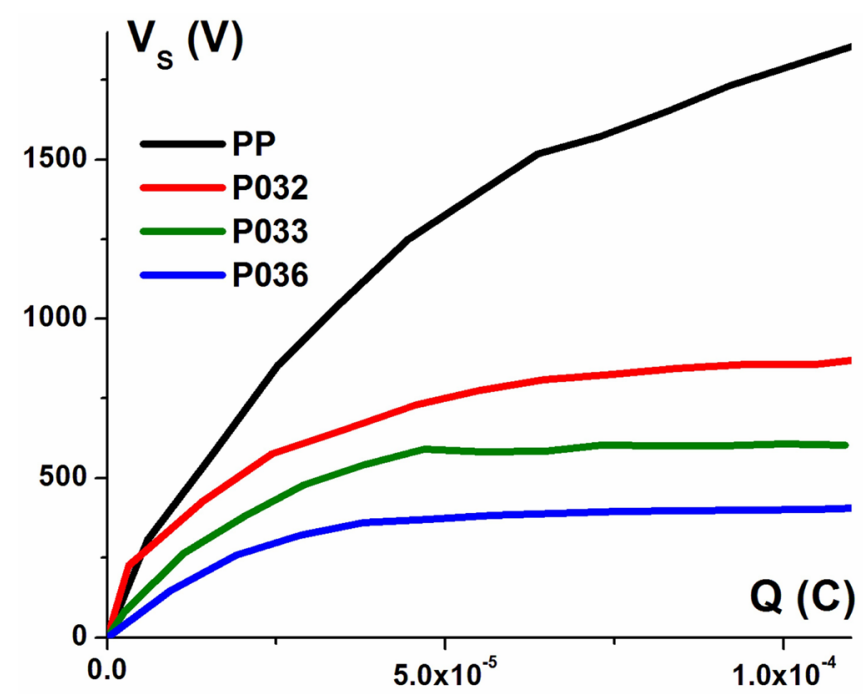

Figure 7. Dependence of the surface potential on the total deposited corona charge for various dielecrtrophores in comparison to the polypropylene film.

Table 1. Estimations of the stored energy density.

\begin{tabular}{ccccc}
\hline & $d(\mu \mathrm{m})$ & $V_{S}(\mathrm{~V})$ & $t_{b d}$ (hours) & $W / M(\mathrm{Wh} / \mathrm{kg})$ \\
\hline PP & 6 & 1856 & 0.003 & 0.9 \\
P032 & 4.1565 & 880 & 2 & 614 \\
P033 & 3.56 & 609 & 5 & 1226 \\
P036 & 2.5985 & 404 & 6 & 1353 \\
\hline
\end{tabular}




\section{Conclusion}

In conclusion, we examined the feasibility to use thin films based on highly polarizable organic molecules, dielectrophores, for the energy storage applications. To examine the response of these films to a high external field, we deposited electric charges on the top surface of the films. The bottom electrode (ITO- or aluminum-coated glass) was connected to the ground and the current accompanied the charge deposition was measured to estimate the amount of the accumulated charges. For calibration, the same experiment was performed on polypropylene films and it showed very good agreement with previous measurements. For dielectrophores, the stored energy density exceeded the polypropylene films by several orders of the magnitude, which makes these materials very attractable for future commercial energy storage applications.

\section{Conflicts of Interest}

The authors declare no conflicts of interest regarding the publication of this paper.

\section{References}

[1] Hao, X. (2013) A Review on the Dielectric Materials for High Energy-Storage Application. Journal of Advanced Dielectrics, 3, 1330001. https://doi.org/10.1142/S2010135X13300016

[2] Mourokh, L., Edder, C., Mack, W. and Lazarev, P. (2018) Molecular Materials for Energy Storage. Materials Sciences and Applications, 9, 517. https://doi.org/10.4236/msa.2018.96036

[3] Mourokh, L. and Lazarev, P. (2017) Energy Storage: Dielectrophores-Molecules with Non-Linear Polarizability. Adv. Mat. Sci., 17, 15. https://doi.org/10.1515/adms-2017-0018

[4] Griffiths, D. (2017) Introduction to Electrodynamics. Cambridge University Press, Cambridge.

[5] Singer, K.D., Sohn, J.E. and Lalama, S.J. (1986) Second Harmonic Generation in Poled Polymer Films. Applied Physics Letters, 49, 248. https://doi.org/10.1063/1.97184

[6] Zhao, Y.-P., Wang, G.-C., Lu, T.-M., Palasantzas, G. and De Hosson, J.Th.M. (1999) Surface-Roughness Effect on Capacitance and Leakage Current of an Insulating Film. Physical Review B, 60, 9157. https://doi.org/10.1103/PhysRevB.60.9157

[7] Loeb, L.B. (1965) Electrical Coronas, Their Basic Physical Mechanisms. University of California Press, Berkley.

[8] Burland, D.M., Miller, R.D. and Walsh, C.A. (1984) Second-Order Nonlinearity in Poled-Polymer Systems. Chemical Reviews, 94, 31. https://doi.org/10.1021/cr00025a002

[9] Puntambekar, K.P., Pesavento, P.V. and Frisbie, C.D. (2004) Surface Potential Profiling and Contact Resistance Measurements on Operating Pentacene Thin-Film Transistors by Kelvin Probe Force Microscopy. Applied Physics Letters, 83, 5539. https://doi.org/10.1063/1.1637443

[10] Deshpande, R.P. (2012) Capacitors: Technology and Trends. Tata McGraw-Hill, New Delhi, 23-49. 
[11] Nahata, A., Shan, J., Yardley, J.T. and Wu, Ch. (1993) Electro-Optic Determination of the Nonlinear-Optical Properties of a Covalently Functionalized Disperse Red 1 Copolymer. Journal of the Optical Society of America B, 10, 1553.

https://doi.org/10.1364/JOSAB.10.001553 